\title{
Comparative efficiency of neuroprotective, glutamatergic and complex therapy of patients with vascular dementia
}

\section{Maksudova Dilnoza Yunusovna}

Andizhan State Medical Institute Assistant of Department of neurology Uzbekistan. Andizhan.

\section{Email address:}

mdyu87@mail.ru (Maksudova Dilnoza Yunusovna)

\section{To cite this article:}

Maksudova Dilnoza Yunusovna. Comparative efficiency of neuroprotective, glutamatergic and complex therapy of patients with vascular dementia. Journal of research in health science. Vol. 1, No. 2, 2018, pp. 79-84. DOI 10.26739/2523-1243

\section{doi http://dx.doi.org/10.26739/2523-1243/-2018-1-2-13}

\begin{abstract}
The problem of dementia in modern medicine becomes one of the most topical problems of nowdays which is associated with marked life quality aggravation of patients suffering from this disease and their disablement.
\end{abstract}

Keywords: Dementia, scales, therapy, cognitive disorders, post-stroce dementia, subcortical dementia.

The article covers the issues related to development of dementiaю. A clinical syndrome characterized by acquired progressive cognitive dysfunction. Not associated with normal age-specific, which affects social adaptation of patients[2]. The author provides accurate definition of mild cognitive disorders as clinical condition , presents its diagnostic criteria and types, as well as diagnostic criteria for dementia associated whith Alzheimer disease, and vascular dementia[1].

The 2nd type diabetes mellitus and cognitive disorders are two most rapid chronic conditions, determining at patients of older 60 years. At this age period $\mathrm{DM}$ is found at $18-20 \%$ of patients, cognitive disorders - on average, at $25 \%$ of patients, including dementia at $6 \%$ of patients, and moderate cognitive disorders at $19 \%$ of patients[4]. For last years prevalence and, respectively, social value of both conditions are increasing for the reason of increasing the number of old people among population. Study of connection between cognitive disorders and DM may help to find one of the ways, preventing from increasing of sickness rate with dementia which, according to the opinion of some specialists, has "chances" to become the main "epidemic" of the XXI century [3].

The analysis of comparative efficiency of various types of therapy in patients with 
Maksudova Dilnoza Yunusovna. Comparative efficiency of neuroprotective, glutamatergic and complex therapy of patients with vascular dementia

diabetic dementia has revealed differences in preparations effect on cognitive and functional constituents depending on the clinical form, dementia gravity and stage of therapy[5].

Comparison of influence efficiency of the studied therapeutic methods according to MMSE scale indicated rather early and evident Gliatiline effect on reliable improvement of overall estimate at the early stage of treatment in diabetic dementia of mild form.
At the furthest stage of attendance the Gliatiline influence on improvement of overall estimate has been considerably marked in subcortical dementia irrespective of the case severity. At the completive stage of attendance the complex therapy with Gliatiline and Alzepile in patients with mild postapoplectic dementia has been occurred to be more effective with regard to scale overall estimate.

Table 1.

Comparative efficiency of preparations according to MMSE (total number in a scale) in patients with diabetic dementia at the beginning and end of the attendance. $\left(\mathrm{M}_{ \pm} \delta\right)$

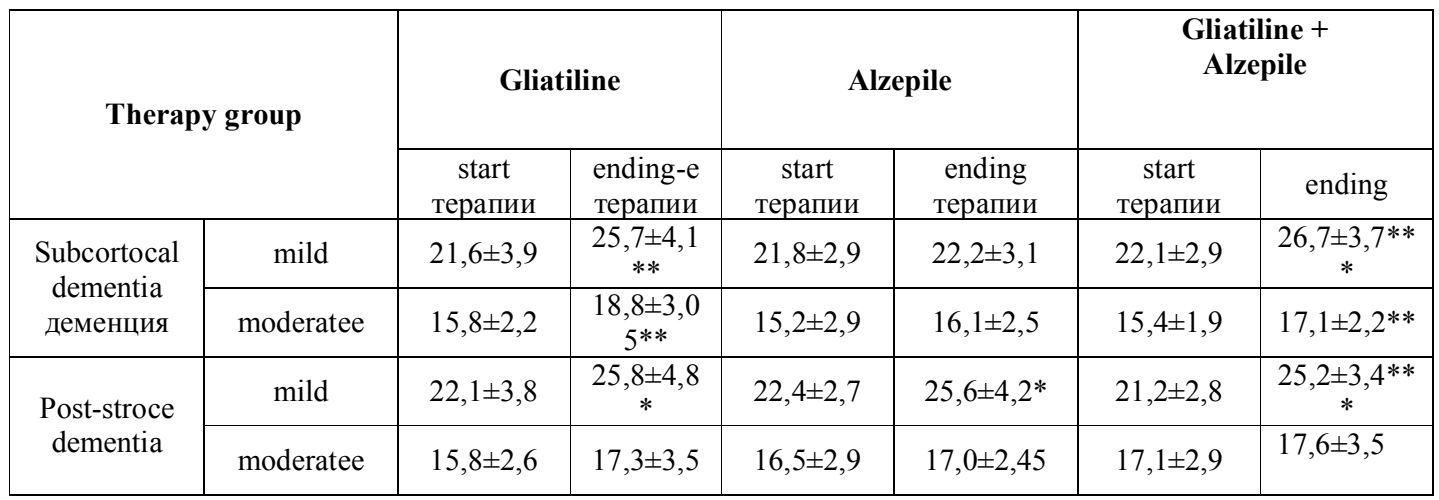

Note: differences as compared with the beginning of therapy are authentic. $\mathbf{p}<0,05, * * \mathbf{p}<0,01, * * * p<0,001$

Comparison of influence efficiency of the three treating methods on separate indices of MMSE scale showed rather early and marked Gliatiline effect on indices of orientation and attention in subcortical dementia irrespective of the case severity, but the preparation influence on information reproduction index has been rather evident in moderate subcortical dementia. In postapoplectic dementia Gliatiline effect occurred to be more effective on speech function.

The complex therapy with Gliatiline and Alzepile proved to have more evident effect on speech indices irrespective of dementia severity in its every clinical form.
In mild postapoplectic dementia the effect of complex therapy has been marked on remembering index, in moderate dementia at the furthest stage of the attendance the attention index has been more improved.

Improvement of orientation and speech indices have been occurred in Alzepile therapy in subcortical and postapoplectic dementia, but in comparison with the effect of the complex therapy and Gliatiline the effect of Alzepile on the given indices has been occurred to be less marked.

In every form of moderate dementia Alzepile therapy proved to be evidently marked on memorization index. 
In every type of therapy over the period of three year-observation some changes in dementia gravity have been taken place in groups of patients of every clinical form of dementia. At the completive stage of three year-observation and therapy in 62 patients $(44,3 \%)$ with mild dementia the overall estimate according to MMSE scale has composed more than 24 points, i.e. severity of cognitive disturbances in these patients turned to be exceeded the limits of dementia, in $31(43,05 \%)$ patients out of them with subcortical dementia and in 31 patients $(45,6 \%)$ - with postapoplactic dementia. In patients with mild form of dementia, irrespective of the clinical form, complex therapy with Gliatiline and Alzepile proved to be more effective with regard to the influence on the severity of dementia, in patients with subcortical dementia - therapy with Gliatiline, in patients with postapoplactic dementia therapy with Alzepile. (Table 12.)

Table 2

Influence of various types of therapy on changes of dementia severity over the course of observation period

\begin{tabular}{|c|c|c|c|c|}
\hline \multirow{3}{*}{\multicolumn{2}{|c|}{ Therapy group }} & \multicolumn{3}{|c|}{ MMSE, total score } \\
\hline & & \multirow{2}{*}{$\begin{array}{c}\text { Initiation of therapy } \\
20-24 \text { score } \\
\end{array}$} & \multicolumn{2}{|c|}{ End of therapy } \\
\hline & & & 20-24 балла & $>24$ баллов \\
\hline \multirow{2}{*}{ Subcortocal dementia } & - Gliatiline & & $13(54,2 \%)$ & $11(45,8 \%)$ \\
\hline & - Alzepile & $24(100 \%)$ & $21(87,5 \%)$ & $3(12,5 \%)$ \\
\hline------- & $\begin{array}{l}\text { - Gliatiline }+ \\
\text { Alzepile } \\
\mathbf{-} \text { - Gliatiline - - - - }\end{array}$ & $\begin{array}{c}24(100 \%) \\
----\overline{23(100 \%)}--\end{array}$ & $\begin{array}{l}5(29,2 \%) \\
-\overline{15}(6 \overline{5,2 \%})\end{array}$ & $\begin{array}{l}17(70,8 \%) \\
-\mathbf{8}(34,8 \%)\end{array}$ \\
\hline \multirow{2}{*}{ Post-stroce dementia } & - Alzepile & $23(100 \%)$ & $12(52,2 \%)$ & $11(47,8 \%)$ \\
\hline & $\begin{array}{l}\text { - Gliatiline }+ \\
\text { Alzepile }\end{array}$ & $22(100 \%)$ & $10(45,5 \%)$ & $12(54,5 \%)$ \\
\hline
\end{tabular}

At the completive moment of three year - observation period and therapy in 31 patients $(23,5 \%)$ with mild dementia the overall estimate according to MMSE scale has composed more than 19 points, i.e. dementia gravity has been changed to the mild case, in 15 patients out of them $(20,8 \%)$ - with subcortical dementia and in 16 patients $(26,6 \%)$ - with postapoplactic dementia. In patients with moderate dementia, irrespective of the clinical form, therapy with Gliatiline has been occurred to be more effective with regard to the influence on the severity of dementia. (Table 13). 
Maksudova Dilnoza Yunusovna. Comparative efficiency of neuroprotective, glutamatergic and complex therapy of patients with vascular dementia

Table 3

Influence of various types of therapy on changes of dementia severity over the course of observation period

\begin{tabular}{|c|c|c|c|c|}
\hline \multirow{3}{*}{\multicolumn{2}{|c|}{ Therapy group }} & \multicolumn{3}{|c|}{ MMSE, total score } \\
\hline & & \multirow{2}{*}{$\begin{array}{c}\text { Initiation of therapy } \\
10-19 \text { score }\end{array}$} & \multicolumn{2}{|c|}{ End of therapy } \\
\hline & & & 10-19 баллов & $>19$ баллов \\
\hline \multirow{3}{*}{$\begin{array}{c}\text { Subcortocal } \\
\text { dementia,number of } \\
\text { patients, }(n, \%)\end{array}$} & - Gliatiline & $24(100 \%)$ & $14(58,4 \%)$ & $10(41,6 \%)$ \\
\hline & - Alzepile & $24(100 \%)$ & $24(100 \%)$ & 0 \\
\hline & $\begin{array}{l}\text { - Gliatiline }+ \\
\text { Alzepile } \\
\text { - Gliatiline }\end{array}$ & $\begin{array}{c}24(100 \%) \\
--\overline{20}(100 \%)\end{array}$ & $\begin{array}{c}19(79,2 \%) \\
14(70 \%)\end{array}$ & $\begin{array}{l}5(20,8 \%) \\
6(30,0 \%)\end{array}$ \\
\hline \multirow{2}{*}{$\begin{array}{l}\text { Post-stroce dementia, } \\
\text { number of patients, (n,\%) }\end{array}$} & - Alzepile & $19(100 \%)$ & $15(78,9 \%)$ & $4(21,05 \%)$ \\
\hline & $\begin{array}{l}\text { - Gliatiline + } \\
\text { Alzepile }\end{array}$ & $21(100 \%)$ & $15(71,4 \%)$ & $6(28,6 \%)$ \\
\hline
\end{tabular}

Estimation of influence efficiency of the therapy according to ADAS-cog+ scale has shown considerably marked effect of the complex therapy with Gliatiline and Alzepile on reducing the total number in a scale at the early stage of therapy irrespective of dementia gravity in its every clinical form.

In subcortical moderate dementia the influence of the given type of therapy on reducing the total number in a scale at the furthest stage of attendance proved to be more clearly marked than the influence by Gliatiline and Alzepile. At the furthest stage of attendance the effect of Gliatiline therapy on reducing the total number in a scale has turned out to be considerably marked in mild cases of subcortical and moderate postapoplactic dementia, and Alzepile therapy has had more evident effect on reducing the total number in a scale in case of mild postapoplactic dementia (Table 14). 
Table 4

Comparative efficiency of preparations according to ADAS-cog (total number in a scale) in patients with diabetic dementia at the beginning and end of observation. $(M \pm \delta)$

\begin{tabular}{|c|c|c|c|c|c|c|c|}
\hline \multirow{2}{*}{\multicolumn{2}{|c|}{ Therapy group }} & \multicolumn{2}{|c|}{ Gliatiline } & \multicolumn{2}{|c|}{ Alzepile } & \multicolumn{2}{|c|}{ Gliatiline + Alzepile } \\
\hline & & $\begin{array}{l}\text { Initiation } \\
\text { of therapy }\end{array}$ & $\begin{array}{l}\text { End of } \\
\text { therapy }\end{array}$ & $\begin{array}{l}\text { Initiation } \\
\text { of } \\
\text { therapy }\end{array}$ & $\begin{array}{l}\text { End of } \\
\text { therapy }\end{array}$ & $\begin{array}{c}\text { Initiation of } \\
\text { therapy }\end{array}$ & $\begin{array}{l}\text { End of } \\
\text { therapy }\end{array}$ \\
\hline \multirow[b]{2}{*}{$\begin{array}{c}\text { Subcortocal } \\
\text { dementia }\end{array}$} & mild & $23,8 \pm 5,4$ & $\begin{array}{c}11,2 \pm 1,5^{* *} \\
*\end{array}$ & $24,0 \pm 5,1$ & $\begin{array}{c}18,6 \pm 4,5^{* *} \\
*\end{array}$ & $23,3 \pm 5,9$ & $\begin{array}{c}12,7 \pm 4,3^{*} \\
* *\end{array}$ \\
\hline & moderate & $37,2 \pm 10,5$ & $\begin{array}{c}25,2 \pm 7,3 * * \\
*\end{array}$ & $29,2 \pm 9,25$ & $\begin{array}{c}21,3 \pm 5,5^{* *} \\
*\end{array}$ & $31,5 \pm 8,5$ & $\begin{array}{c}17,5 \pm 2,1^{*} \\
* *\end{array}$ \\
\hline \multirow[b]{2}{*}{$\begin{array}{c}\text { Post- stroce } \\
\text { dementia }\end{array}$} & mild & $23,1 \pm 7,4$ & $\begin{array}{c}13,25 \pm 7,6^{*} \\
* *\end{array}$ & $26,0 \pm 8,4$ & $\begin{array}{c}14,0 \pm 4,3^{* *} \\
*\end{array}$ & $18,4 \pm 3,9$ & $\begin{array}{c}9,8 \pm 1,8 * * \\
*\end{array}$ \\
\hline & moderate & $27,6 \pm 7,7$ & $\begin{array}{c}15,8 \pm 8,4^{* *} \\
*\end{array}$ & $28,5 \pm 4,7$ & $\begin{array}{c}18,0 \pm 2,75^{*} \\
* *\end{array}$ & $28,0 \pm 4,75$ & $\begin{array}{c}17,0 \pm 2,5^{*} \\
* *\end{array}$ \\
\hline
\end{tabular}

Note: differences as compared with the beginning of therapy are authentic. $\mathbf{p}<0,05,{ }^{* *} \mathbf{p}<0,01, * * * \mathbf{p}<0,001$

While comparing the influence efficiency of the three therapeutic methods on separate indices of ADAS-cog+ scale it has been revealed rather early and marked Gliatiline effect on indices of memory, learning, acquisition of new information, constructive praxis and executive functions in case of mild dementia irrespective of the clinical form.

Complex therapy with Gliatiline and Alzepile at the furthest stage of attendance proved to have rather evident influence on visual attention regardless of dementia gravity in its every form. In case of mild subcortical dementia - on praxis indices. By means of complex therapy in every clinical form of dementia at the furthest stage of attendance the improvement of indices of memory, learning, acquisition of new information have been noted, but in comparison with the effect of Gliatiline therapy, the effect of complex therapy on the given indices has been less marked.

Alzepile therapy has greater influence on improvement the indices of praxis and understanding of the speech in moderate subcortical dementia, in postapoplactic dementia the Alzepile therapy improves the indices of visual attention as well as with complex treatment improves the indices of executive functions.

Estimation of influence efficiency of the therapy according to MoCa test scale has shown, that Gliatiline has rather early and marked influence on the indices of intellectual functioning of patients in subcortical dementia irrespective of the case severity. In postapoplactic dementia Gliatiline has more effect on the indices of every-day and motional activities. Complex therapy with Gliatiline and Alzepile at the early stage mostly 
Maksudova Dilnoza Yunusovna. Comparative efficiency of neuroprotective, glutamatergic and complex therapy of patients with vascular dementia

influences on the patient's abilities for self-service and self-care, motional activity and daily contact in every clinical form of dementia irrespective of the case severity. Alzepile therapy influences on improvement of indices of intellectual functioning of patients, common and motional activities in every form of dementia, but in comparison with the effect of complex therapy with Gliatiline, the effect of Alzepile therapy on the given indices has been less marked.

Estimation of influence efficiency of therapeutic methods on the rate of cognitive processes and executive functions of patients has showed rather early and greater effect of Gliatiline therapy in every clinical form of mild dementia. At the the furthest stage Gliatiline effect proved to be considerably evident in mild subcortical dementia, and in moderate subcortical dementia - the effect of complex therapy by preparations.

Estimation of influence efficiency of therapeutic methods on optical-space gnosis has revealed rather early and greater influence of Gliatiline therapy in postapoplactic dementia irrespective of the case severity. At the the furthest stage of attendance Alzepile effect on improvement test estimation has been greater marked than the effect of complex therapy and Gliatiline. Influence of the complex therapy by preparations on the space functions in subcortical dementia proved to be considerably marked as well as at the early stage and at the furthest stage of attendance irrespective of dementia gravity.

\section{References:}

1. DCCT Research Group. Effects of intensive diabetes therapy neuropsychological function in adults in the Diabetes Control and Complications Trial.// Ann. Intern. Med. -1996.-Vol. 124. - P.379388.

2. CCT Research Group. The Effect of Intensive Treatment of Diabetes on the Development and Progression of Long-Term Complications in Insulin-Dependent Diabetes Mellitus. // New England Journal of Medicine.

3. Gregg E.W., Engelgau M.E., Narayan K.M.V. Cognitive decline, physical disability, and other unappreciated outcomes of diabetes and aging. // BMJ. 2002. - Vol.325.-P.916-917

4. Petersen R. S. Current concepts in mild cognitive impairment // Arch. Neurol. 2001. - Vol. 58. - P. $1985-1992$.

5.Posner H.B., Tang M.-X., Luchsinger J.The relationship of hypertension in the elderly to AD, vascular dementia, and cognitive function // Neurology. Vol. 2002 (58) P.1175-1181. 